\title{
An affirmative answer to Panyanak and Suantai's open question on the viscosity approximation methods for a nonexpansive multi-valued mapping in CAT(0) spaces
}

\author{
Shih-Sen Chang ${ }^{\mathrm{a}}$, Lin Wang ${ }^{\mathrm{b}, *}$, Jen-Chih Yao ${ }^{\mathrm{a}}$, Li Yang ${ }^{\mathrm{c}}$ \\ ${ }^{a}$ Center for General Education, China Medical University, Taichung, 40402, Taiwan. \\ ${ }^{b}$ College of Statistics and Mathematics, Yunnan University of Finance and Economics, Kunming, Yunnan 650221, China. \\ ${ }^{c}$ Department of Mathematics, South West University of Science and Technology, Mianyang, Sichuan 621010, China.
}

Communicated by X. Qin

\begin{abstract}
An affirmative answer to the open question raised by Panyanak and Suantai [B. Panyanak, S. Suantai, Fixed Point Theory Appl., 2015 (2015), 14 pages] is given. Our results also generalize the results of Panyanak and Suantai [B. Panyanak, S. Suantai, Fixed Point Theory Appl., 2015 (2015), 14 pages], Wangkeeree and Preechasilp [R. Wangkeeree, P. Preechasilp, J. Inequal. Appl., 2013 (2013), 15 pages], Dhompongsa et al. [S. Dhompongsa, A. Kaewkhao, B. Panyanak, Nonlinear Anal., 75 (2012), 459-468], and many others. Some related results in R-trees are also proved. (C)2017 All rights reserved.
\end{abstract}

Keywords: Viscosity approximation method, fixed point, strong convergence, multivalued nonexpansive mapping, CAT(0) space.

2010 MSC: 47H09, 47J25.

\section{Introduction and preliminaries}

Let $E$ be a nonempty closed convex subset of a Hilbert space $H$ and $T: E \rightarrow E$ be a nonexpansive mapping with a nonempty fixed point set $F i x(T)$. The following scheme is known as the viscosity approximation method or Moudafi's viscosity approximation method: for any given $x_{1} \in E$,

$$
x_{n+1}=\alpha_{n} f\left(x_{n}\right)+\left(1-\alpha_{n}\right) T\left(x_{n}\right), \quad \forall n \geqslant 1,
$$

where $f: E \rightarrow E$ is a contraction and $\left\{\alpha_{n}\right\}$ is a sequence in $(0,1)$. In [13], under some suitable assumptions, the author proved that the sequence $\left\{x_{n}\right\}$ defined by (1.1) converges strongly to a point $z \in$ Fix $(T)$ which satisfies the following variational inequality:

$$
\langle f(z)-z, z-x\rangle \geqslant 0, \quad \forall x \in \operatorname{Fix}(T) .
$$

\footnotetext{
*Corresponding author

Email addresses: changss2013@163.com (Shih-Sen Chang), wanglin64@outlook.com (Lin Wang), yaojc@mail.cmu.edu.tw (Jen-Chih Yao), yangli@swust.edu.cn (Li Yang)

doi:10.22436/jnsa.010.05.38
}

Received 2016-10-27 
We note that the Moudafi viscosity approximation method can be applied to convex optimization, linear programming, monotone inclusions, and elliptic differential equations.

The first extension of Moudafi's result to the so-called CAT(0) space was proved by Shi and Chen [17]. However, they assumed that the space CAT(0) must satisfy some addition condition P. By using the concept of quasi-linearization introduced by Berg and Nikolaev [2], Wangkeeree and Preechasilp [19] could omit the condition P from Shi and Chen's result. They obtained the following theorems.

Theorem 1.1 ([19, Theorem 3.1]). Let $\mathrm{E}$ be a nonempty closed and convex subset of a complete CAT(0) space $\mathrm{X}$, $\mathrm{T}: \mathrm{E} \rightarrow \mathrm{E}$ be a nonexpansive mapping with $\mathrm{Fix}(\mathrm{T}) \neq \emptyset$, and $\mathrm{f}: \mathrm{E} \rightarrow \mathrm{E}$ be a contraction with constant $\mathrm{k} \in(0,1)$. For each $\mathrm{s} \in(0,1)$, let $\mathrm{x}_{\mathrm{s}}$ be given by

$$
x_{s}=\operatorname{sf}\left(x_{s}\right) \oplus(1-s) T\left(x_{s}\right) .
$$

Then the net $\left\{x_{s}\right\}$ converges strongly to $\tilde{x}$ as $s \rightarrow 0$ such that $\tilde{x}=P_{\mathrm{Fix}(\mathrm{T})}(f(\tilde{x}))$, which is equivalent to the variational inequality:

$$
\langle\overrightarrow{\tilde{x} f(\tilde{x})}, \overrightarrow{x \tilde{x}}\rangle \geqslant 0, \quad \forall x \in \operatorname{Fix}(T) .
$$

Theorem 1.2 ([19, Theorem 3.4]). Let $\mathrm{E}, \mathrm{X}, \mathrm{T}, \mathrm{f}, \mathrm{k}$ be the same as in Theorem 1.1. Suppose that $\mathrm{x}_{1} \in \mathrm{E}$ is arbitrarily chosen and $\left\{x_{n}\right\}$ is iteratively generated by

$$
x_{n+1}=\alpha_{n} f\left(x_{n}\right) \oplus\left(1-\alpha_{n}\right) T\left(x_{n}\right), \quad \forall n \geqslant 1,
$$

where $\left\{\alpha_{n}\right\}$ is a sequence in $\left(0, \frac{1}{2-k}\right)$ satisfying:

(C1) $\lim _{n \rightarrow \infty} \alpha_{n}=0$;

(C2) $\sum_{n=1}^{\infty} \alpha_{n}=\infty$;

(C3) $\sum_{n=1}^{\infty}\left|\alpha_{n}-\alpha_{n+1}\right|<\infty$ or $\lim _{n \rightarrow \infty} \frac{\alpha_{n}}{\alpha_{n+1}}=1$.

Then $\left\{x_{n}\right\}$ converges strongly to $\tilde{x}$, where $\tilde{x}=P_{\mathrm{Fix}(\mathrm{T})}(\mathrm{f}(\tilde{\mathrm{x}}))$.

As is well-known that fixed point theory for multivalued mappings has many useful applications in applied sciences, in particular, in game theory and optimization theory. Thus, it is natural to study the extension of the known fixed point results for single-valued mappings to the setting of multivalued mappings.

Very recently, Panyanak and Suantai [15] by using the endpoint condition extended Theorems 1.1 and 1.2 to multivalued nonexpansive mappings and proved the following results.

Theorem 1.3 ([15, Theorem 3.3]). Let $\mathrm{E}$ be a nonempty closed convex subset of a complete CAT(0) space $\mathrm{X}$ and $\mathrm{K}(\mathrm{E})$ be the family of all nonempty compact subsets of $\mathrm{E}$. Let $\mathrm{T}: \mathrm{E} \rightarrow \mathrm{K}(\mathrm{E})$ be a nonexpansive mapping satisfying the endpoint condition. Let $\mathrm{f}: \mathrm{E} \rightarrow \mathrm{E}$ be a contraction with $\mathrm{k} \in\left(0, \frac{1}{2}\right)$ and $\left\{\alpha_{n}\right\}$ be a sequence in $\left(0, \frac{1}{2-\mathrm{k}}\right)$ satisfying the conditions (C1), (C2), (C3) in Theorem 1.2. For given $x_{1} \in \mathrm{E}$, let $\left\{x_{n}\right\}$ be a sequence defined by

$$
x_{n+1}=\alpha_{n} f\left(x_{n}\right) \oplus\left(1-\alpha_{n}\right) y_{n}, \quad y_{n} \in T\left(x_{n}\right),
$$

with

$$
\mathrm{d}\left(\mathrm{y}_{\mathrm{n}}, \mathrm{y}_{\mathrm{n}+1}\right) \leqslant \mathrm{d}\left(\mathrm{x}_{\mathrm{n}}, \mathrm{x}_{\mathrm{n}+1}\right), \quad \forall \mathrm{n} \geqslant 1 .
$$

Then the sequence $\left\{x_{n}\right\}$ defined by (1.2) converges strongly to $\tilde{x}$, where $\tilde{x}=P_{F i x(T)}(f(\tilde{x}))$.

They also put forward the following.

Open Question 1.4 ([15]). Let $\mathrm{E}$ be a nonempty closed convex subset of a complete $\mathrm{CAT}(0)$ space $\mathrm{X}, \mathrm{T}: \mathrm{E} \rightarrow \mathrm{K}(\mathrm{E})$ be a nonexpansive mapping satisfying the endpoint condition. Let $\mathrm{f}: \mathrm{E} \rightarrow \mathrm{E}$ be a contraction with $\mathrm{k} \in[0,1)$ and $\left\{\alpha_{n}\right\}$ be a sequence in $(0,1)$ satisfying the conditions (C1), (C2) and (C3) in Theorem 1.2, and $\left\{x_{n}\right\}$ be the sequence defined by (1.2). Does $\left\{x_{n}\right\}$ converge strongly to $\tilde{x}=P_{F i x(T)}(f(\tilde{x}))$ ?

The purpose of this paper is to prove a strong convergence theorem of the viscosity approximation method for multivalued nonexpansive mappings in CAT(0) spaces. Our results not only give an affirmative answer to Panyanak and Suantai's open question but also generalize the results of Panyanak and Suantai [15], Wangkeeree and Preechasilp [19], and Dhompongsa et al. [6] and many others. Some related results in R-trees are also given. 


\section{Preliminaries and lemmas}

Recall that a metric space $(X, d)$ is called a CAT(0) space, if it is geodesically connected and if every geodesic triangle in $X$ is at least as 'thin' as its comparison triangle in the Euclidean plane. It is known that any complete, simply connected Riemannian manifold having non-positive sectional curvature is a CAT(0) space. Other examples of CAT(0) spaces include pre-Hilbert spaces (see [3]), R-trees (see [11]), Euclidean buildings (see [4]), the complex Hilbert ball with a hyperbolic metric (see [9]), and many others. A complete CAT(0) space is often called Hadamard space. A subset $\mathrm{K}$ of a CAT(0) space $\mathrm{X}$ is convex, if for any $x, y \in K$, we have $[x, y] \subset K$, where $[x, y]$ is the uniquely geodesic joining $x$ and $y$.

In this paper, we write $(1-t) x \oplus t y$ for the unique point $z$ in the geodesic segment joining from $x$ to $y$ such that

$$
d(x, z)=\operatorname{td}(x, y), \quad d(y, z)=(1-t) d(x, y) .
$$

It is well-known that a geodesic space $(X, d)$ is a CAT(0) space, if and only if the following inequality

$$
d^{2}((1-t) x \oplus t y, z) \leqslant(1-t) d^{2}(x, z)+t d^{2}(y, z)-t(1-t) d^{2}(x, y),
$$

is satisfied for all $x, y, z \in X$ and $t \in[0,1]$. In particular, if $x, y, z$ are points in a CAT(0) space $(X, d)$ and $t \in[0,1]$, then

$$
d((1-t) x \oplus t y, z) \leqslant(1-t) d(x, z)+t d(y, z) .
$$

The concept of quasi-linearization was introduced by Berg and Nikolaev [2]. Let $(X, d)$ be a metric space. We denote a pair $(a, b) \in X \times X$ by $\overrightarrow{a b}$ and call it a vector. The quasi-linearization is a mapping $\langle\cdot, \cdot\rangle:(\mathrm{X} \times \mathrm{X}) \times(\mathrm{X} \times \mathrm{X}) \rightarrow \mathbb{R}$ defined by

$$
\langle\overrightarrow{a b}, \overrightarrow{c d}\rangle=\frac{1}{2}\left(d^{2}(a, d)+d^{2}(b, c)-d^{2}(a, c)-d^{2}(b, d)\right), \quad \forall a, b, c, d \in X .
$$

It is easy to see that $\langle\overrightarrow{a b}, \overrightarrow{c d}\rangle=\langle\overrightarrow{c d}, \overrightarrow{a b}\rangle,\langle\overrightarrow{a b}, \overrightarrow{c d}\rangle=-\langle\overrightarrow{b a}, \overrightarrow{c d}\rangle$ and $\langle\overrightarrow{a x}, \overrightarrow{c d}\rangle+\langle\overrightarrow{x b}, \overrightarrow{c d}\rangle=\langle\overrightarrow{a b}, \overrightarrow{c d}\rangle$ for all $a, b, c, d \in X$.

We say that $(X, d)$ satisfies the Cauchy-Schwarz inequality, if

$$
|\langle\overrightarrow{a b}, \overrightarrow{c d}\rangle| \leqslant d(a, b) d(c, d), \quad \forall a, b, c, d \in X .
$$

It is well-known [2] that $(X, d)$ is a CAT(0) space if and only if it satisfies the Cauchy-Schwarz inequality. Some other properties of quasi-linearization are included as follows.

Lemma 2.1 ([7, 8]). Let $\mathrm{C}$ be a nonempty convex subset of a complete $C A T(0)$ space $(\mathrm{X}, \mathrm{d}), \mathrm{x} \in \mathrm{X}$ and $\mathrm{u} \in \mathrm{C}$. Then $\mathrm{u}=\mathrm{P}_{\mathrm{C}}(\mathrm{x})$ (the metric projection of $\mathrm{x}$ to $\mathrm{C}$ ) if and only if

$$
\langle\overrightarrow{y u}, \overrightarrow{u x}\rangle \geqslant 0, \quad \forall y \in C
$$

Lemma 2.2 ([20]). Let $\mathrm{X}$ be a complete $C A T(0)$ space. For any $\mathrm{t} \in[0,1]$ and $\mathrm{u}, \boldsymbol{v} \in \mathrm{X}$, let $\mathrm{u}_{\mathrm{t}}=\mathrm{tu} \oplus(1-\mathrm{t}) \boldsymbol{v}$. Then, for any $x, y \in X$,

(i) $\left\langle\overrightarrow{u_{t} x}, \overrightarrow{u_{t} y}\right\rangle \leqslant t\left\langle\overrightarrow{u x}, \overrightarrow{u_{t} \vec{y}}\right\rangle+(1-t)\left\langle\overrightarrow{v x}, \overrightarrow{u_{t} y}\right\rangle ;$

(ii) $\left\langle\overrightarrow{u_{t}}, \overrightarrow{u y}\right\rangle \leqslant t\langle\overrightarrow{u x}, \overrightarrow{u y}\rangle+(1-t)\langle\overrightarrow{v x}, \overrightarrow{u y}\rangle$ and $\left\langle\overrightarrow{u_{t} x}, \overrightarrow{v y}\right\rangle \leqslant t\langle\overrightarrow{u x}, \overrightarrow{v y}\rangle+(1-t)\langle\overrightarrow{v x}, \overrightarrow{v y}\rangle$.

Recall that a continuous linear functional $\mu$ on $l^{\infty}$, the Banach space of bounded real sequences is called a Banach limit, if $\|\mu\|=\mu(1,1,1, \cdots)=1$ and $\mu_{n}\left(a_{n}\right)=\mu_{n}\left(a_{n+1}\right)$ for all $\left\{a_{n}\right\} \in l^{\infty}$.

Lemma 2.3 ([18]). Let $\alpha$ be a real number and let $\left(a_{1}, a_{2}, \cdots\right) \in l^{\infty}$ be such that $\mu_{n}\left(a_{n}\right) \leqslant \alpha$ for all Banach limits $\mu$ and $\lim \sup _{n \rightarrow \infty}\left(a_{n+1}-a_{n}\right) \leqslant 0$. Then $\limsup _{n \rightarrow \infty} a_{n} \leqslant \alpha$. 
Lemma 2.4 ([21]). Let $\left\{c_{n}\right\}$ be a sequence of non-negative real numbers satisfying the property

$$
c_{n+1} \leqslant\left(1-\gamma_{n}\right) c_{n}+\gamma_{n} \eta_{n}, \quad n \geqslant 1,
$$

where $\left\{\gamma_{n}\right\} \subset(0,1)$ and $\left\{\eta_{n}\right\} \subset \mathbb{R}$ such that

(i) $\sum_{n=1}^{\infty} \gamma_{n}=\infty$;

(ii) $\limsup _{n \rightarrow \infty} \eta_{n} \leqslant 0$ or $\sum_{n=1}^{\infty}\left|\gamma_{n} \eta_{n}\right|<\infty$.

Then $\left\{\mathrm{c}_{\mathrm{n}}\right\}$ converges to zero as $\mathrm{n} \rightarrow \infty$.

Definition 2.5. A multivalued mapping $T: E \rightarrow B C(X)$ is said to be nonexpansive, if

$$
H(T(x), T(y)) \leqslant d(x, y), \quad x, y \in E .
$$

A point $x \in E$ is called a fixed point of $T$ if $x \in T(x)$. We shall denote by $F i x(T)$ the set of all fixed points of T. A multivalued mapping $T$ is said to satisfy the endpoint condition [5], if $F i x(T) \neq \emptyset$ and $T(x)=\{x\}$ for all $x \in \operatorname{Fix}(T)$.

Lemma 2.6 ([15, Theorem 3.1]). Let $\mathrm{E}$ be a nonempty closed convex subset of a complete CAT(0) space $\mathrm{X}$ and $\mathrm{K}(\mathrm{E})$ be the family of all nonempty compact subsets of $\mathrm{E}$. Let $\mathrm{T}: \mathrm{E} \rightarrow \mathrm{K}(\mathrm{E})$ be a nonexpansive mapping satisfying the endpoint condition, and $\mathrm{f}: \mathrm{E} \rightarrow \mathrm{E}$ be a contraction with $\mathrm{k} \in(0,1)$. Then the following statements hold:

(i) the net $\left\{x_{s}\right\}$ defined by

$$
x_{s} \in \operatorname{sf}\left(x_{s}\right) \oplus(1-s) T\left(x_{s}\right), \quad s \in(0,1),
$$

converges strongly to $\tilde{\mathrm{x}}$ as $\mathrm{s} \rightarrow 0$ where $\tilde{\mathrm{x}}=\mathrm{P}_{\mathrm{Fix}(\mathrm{T})}(\mathrm{f}(\tilde{\mathrm{x}}))$;

(ii) if $\left\{x_{n}\right\}$ is a bounded sequence in $E$ such that $\lim _{n \rightarrow \infty} \mathrm{d}\left(\mathrm{x}_{\mathrm{n}}, \mathrm{T}\left(\mathrm{x}_{\mathrm{n}}\right)\right)=0$, then

$$
d^{2}(f(\tilde{x}), \tilde{x}) \leqslant \mu_{n} d^{2}\left(f(\tilde{x}), x_{n}\right),
$$

for all Banach limits $\mu$.

Let $E$ be a nonempty subset of a $\operatorname{CAT}(0)$ space $(X, d)$. We shall denote the family of nonempty bounded and closed subsets of $E$ by $B C(E)$, the family of nonempty bounded and closed convex subsets of $E$ by $\mathrm{BCC}(\mathrm{E})$, and the family of nonempty compact subsets of $E$ by $\mathrm{K}(\mathrm{E})$. Let $\mathrm{H}(\cdot, \cdot)$ be the Hausdorff distance on $\mathrm{BC}(\mathrm{X})$ defined by

$$
H(A, B)=\max \left\{\sup _{a \in A} d(a, B), \sup _{b \in B} d(b, A)\right\}, \quad A, B \in B C(X),
$$

where $d(a, B):=\inf \{d(a, b): b \in B\}$ is the distance from the point $a$ to the set $B$.

Lemma 2.7 (Nadler [14]). Let (X, d) be a metric space, E be a nonempty and closed subset of $X$, and $A, B \in K(E)$. Then for any given $\mathrm{a} \in \mathrm{A}$, there exists a point $\mathrm{b} \in \mathrm{B}$ such that

$$
d(a, b) \leqslant H(A, B) .
$$

\section{Main results}

We are now in a position to give the main results of the paper.

Theorem 3.1. Let $\mathrm{E}$ be a nonempty closed convex subset of a complete $\mathrm{CAT}(0)$ space $\mathrm{X}, \mathrm{T}: \mathrm{E} \rightarrow \mathrm{K}(\mathrm{E})$ be a nonexpansive mapping satisfying the endpoint condition. Let $\mathrm{f}: \mathrm{E} \rightarrow \mathrm{E}$ be a contraction with $\mathrm{k} \in(0,1)$ and $\left\{\alpha_{\mathrm{n}}\right\}$ be a sequence in $(0,1)$ satisfying the following conditions:

(C1) $\lim _{n \rightarrow \infty} \alpha_{n}=0$; 
(C2) $\sum_{n=1}^{\infty} \alpha_{n}=\infty$;

(C3) $\sum_{n=1}^{\infty}\left|\alpha_{n}-\alpha_{n+1}\right|<\infty$ or $\lim _{n \rightarrow \infty} \frac{\alpha_{n}}{\alpha_{n+1}}=1$.

Then the sequence $\left\{x_{n}\right\}$ defined by (1.2) converges strongly to $\tilde{x}$, where $\tilde{x}=P_{F i x(T)}(f(\tilde{x}))$.

Proof. We divide the proof into four steps.

Step 1: We show that $\left\{x_{n}\right\},\left\{y_{n}\right\}$, and $\left\{f\left(x_{n}\right)\right\}$ are bounded sequences in E. Let $p \in F i x(T)$. By inequality (2.2) we have

$$
\begin{aligned}
d\left(x_{n+1}, p\right) & \leqslant \alpha_{n} d\left(f\left(x_{n}\right), p\right)+\left(1-\alpha_{n}\right) d\left(y_{n}, p\right) \\
& \leqslant \alpha_{n}\left[d\left(f\left(x_{n}\right), f(p)\right)+d(f(p), p)\right]+\left(1-\alpha_{n}\right) H\left(T\left(x_{n}\right), T(p)\right) \\
& \leqslant \alpha_{n}\left[d\left(f\left(x_{n}\right), f(p)\right)+d(f(p), p)\right]+\left(1-\alpha_{n}\right) d\left(x_{n}, p\right) \\
& \leqslant \alpha_{n} k d\left(x_{n}, p\right)+\alpha_{n} d(f(p), p)+\left(1-\alpha_{n}\right) d\left(x_{n}, p\right) \\
& =\left(1-\alpha_{n}(1-k)\right) d\left(x_{n}, p\right)+\alpha_{n} d(f(p), p) \\
& \leqslant \max \left\{d\left(x_{n}, p\right), \frac{d(f(p), p)}{1-k}\right\} .
\end{aligned}
$$

By induction, we have

$$
d\left(x_{n}, p\right) \leqslant \max \left\{d\left(x_{1}, p\right), \frac{d(f(p), p)}{1-k}\right\}, \quad \forall n \geqslant 1 .
$$

Hence, $\left\{x_{n}\right\}$ is bounded, so is $\left\{f\left(x_{n}\right)\right\}$. Again since

$$
d\left(y_{n}, p\right) \leqslant H\left(T x_{n}, T p\right) \leqslant d\left(x_{n}, p\right) .
$$

This implies that $\left\{y_{n}\right\}$ is also bounded.

Step 2: Next we show that

$$
\lim _{n \rightarrow \infty} d\left(x_{n+1}, x_{n}\right)=0
$$

In fact, we have

$$
\begin{aligned}
d\left(x_{n+1}, x_{n}\right) \leqslant & d\left(\alpha_{n} f\left(x_{n}\right) \oplus\left(1-\alpha_{n}\right) y_{n}, \alpha_{n-1} f\left(x_{n-1}\right) \oplus\left(1-\alpha_{n-1}\right) y_{n-1}\right) \\
\leqslant & d\left(\alpha_{n} f\left(x_{n}\right) \oplus\left(1-\alpha_{n}\right) y_{n}, \alpha_{n} f\left(x_{n}\right) \oplus\left(1-\alpha_{n}\right) y_{n-1}\right) \\
& +d\left(\alpha_{n} f\left(x_{n}\right) \oplus\left(1-\alpha_{n}\right) y_{n-1}, \alpha_{n} f\left(x_{n-1}\right) \oplus\left(1-\alpha_{n}\right) y_{n-1}\right) \\
& +d\left(\alpha_{n} f\left(x_{n-1}\right) \oplus\left(1-\alpha_{n}\right) y_{n-1}, \alpha_{n-1} f\left(x_{n-1}\right) \oplus\left(1-\alpha_{n-1}\right) y_{n-1}\right) \\
\leqslant & \left(1-\alpha_{n}\right) d\left(y_{n}, y_{n-1}\right)+\alpha_{n} d\left(f\left(x_{n}\right), f\left(x_{n-1}\right)\right) \\
& \left.+\left|\alpha_{n}-\alpha_{n-1}\right| d\left(f\left(x_{n-1}\right), y_{n-1}\right) \quad \text { (by condition }(1.3)\right) \\
\leqslant & \left(1-\alpha_{n}(1-k)\right) d\left(x_{n}, x_{n-1}\right)+\left|\alpha_{n}-\alpha_{n-1}\right| d\left(f\left(x_{n-1}\right), y_{n-1}\right) .
\end{aligned}
$$

Putting, in Lemma 2.4,

$$
c_{n}=d\left(x_{n}, x_{n-1}\right), \quad \gamma_{n}=(1-k) \alpha_{n},
$$

and

$$
\eta_{n}=\frac{1}{1-k}\left|1-\frac{\alpha_{n-1}}{\alpha_{n}}\right| d\left(f\left(x_{n-1}\right), y_{n-1}\right),
$$

from conditions (C1), (C2) and (C3), we get that $\lim _{n \rightarrow \infty} d\left(x_{n+1}, x_{n}\right)=0$.

Step 3: Next we show that

$$
\lim _{n \rightarrow \infty} d\left(x_{n}, T\left(x_{n}\right)\right)=0, \quad \lim _{n \rightarrow \infty} d\left(x_{n}, y_{n}\right)=0, \quad \lim _{n \rightarrow \infty} d\left(y_{n}, y_{n+1}\right)=0, \quad \lim _{n \rightarrow \infty} d\left(y_{n}, T\left(y_{n}\right)\right)=0
$$


In fact, it follows from (3.1) and condition (C1) that

$$
\begin{aligned}
d\left(x_{n}, T\left(x_{n}\right)\right) & \leqslant d\left(x_{n}, y_{n}\right) \\
& \leqslant d\left(x_{n}, x_{n+1}\right)+d\left(x_{n+1}, y_{n}\right) \\
& \leqslant d\left(x_{n}, x_{n+1}\right)+\alpha_{n} d\left(f\left(x_{n}\right), y_{n}\right) \rightarrow 0 \text { as } n \rightarrow \infty .
\end{aligned}
$$

By (1.2) and (2.2) we have

$$
d\left(x_{n+1}, y_{n}\right)=d\left(\alpha_{n} f\left(x_{n}\right) \oplus\left(1-\alpha_{n}\right) y_{n}, y_{n}\right) \leqslant \alpha_{n} d\left(f\left(x_{n}\right), y_{n}\right) \rightarrow 0, \text { as } n \rightarrow \infty .
$$

Hence we have

$$
d\left(x_{n}, y_{n}\right) \leqslant d\left(x_{n}, x_{n+1}\right)+d\left(x_{n+1}, y_{n}\right) \rightarrow 0, \text { as } n \rightarrow \infty,
$$

and

$$
d\left(y_{n+1}, y_{n}\right) \leqslant d\left(y_{n+1}, x_{n+1}\right)+d\left(x_{n+1}, x_{n}\right)+d\left(x_{n}, y_{n}\right) \rightarrow 0, \text { as } n \rightarrow \infty .
$$

It follows from (3.3) and (3.4) that

$$
d\left(y_{n}, T\left(y_{n}\right)\right) \leqslant d\left(y_{n} \cdot x_{n}\right)+d\left(x_{n}, T x_{n}\right)+H\left(T x_{n}, T y_{n}\right) \leqslant 2 d\left(y_{n} \cdot x_{n}\right)+d\left(x_{n}, T x_{n}\right) \rightarrow 0 \text { as } n \rightarrow \infty .
$$

Step 4: Next we show that $\left\{x_{n}\right\}$ converges strongly to a point $\tilde{x} \in \operatorname{Fix}(T)$ with $\tilde{x}=P_{\text {Fix }(T)}(f(\tilde{x}))$.

For each $s \in(0,1)$, let $x_{s}$ be defined by (2.5). By Lemma 2.6, $\left\{x_{s}\right\}$ converges strongly to a point $\tilde{x} \in \operatorname{Fix}(T)$ and $\tilde{x}=P_{\mathrm{Fix}(\mathrm{T})}(\mathrm{f}(\tilde{\mathrm{x}}))$.

By (3.2) $\lim _{n \rightarrow \infty} d\left(y_{n}, T\left(y_{n}\right)\right)=0$, therefore from Lemma 2.6 (ii) we have that

$$
d^{2}(f(\tilde{x}), \tilde{x}) \leqslant \mu_{n} d^{2}\left(f(\tilde{x}), y_{n}\right),
$$

for all Banach limits $\mu$.

Moreover, since $\lim _{n \rightarrow \infty} d\left(y_{n+1}, y_{n}\right)=0$,

$$
\limsup _{n \rightarrow \infty}\left[d^{2}(f(\tilde{x}), \tilde{x})-d^{2}\left(f(\tilde{x}), y_{n+1}\right)-\left(d^{2}(f(\tilde{x}), \tilde{x})-d^{2}\left(f(\tilde{x}), y_{n}\right)\right)\right] \leqslant 0 .
$$

It follows from Lemma 2.3 that

$$
\limsup _{n \rightarrow \infty}\left(d^{2}(f(\tilde{x}), \tilde{x})-d^{2}\left(f(\tilde{x}), y_{n}\right)\right) \leqslant 0 .
$$

Furthermore, from (2.1) and Lemma 2.2 we have that

$$
\begin{aligned}
d^{2}\left(x_{n+1}, \tilde{x}\right) & =d^{2}\left(\alpha_{n} f\left(x_{n}\right) \oplus\left(1-\alpha_{n}\right) y_{n}, \tilde{x}\right) \\
& \leqslant \alpha_{n} d^{2}\left(f\left(x_{n}\right), \tilde{x}\right)+\left(1-\alpha_{n}\right) d^{2}\left(y_{n}, \tilde{x}\right)-\alpha_{n}\left(1-\alpha_{n}\right) d^{2}\left(f\left(x_{n}\right), y_{n}\right) \\
& =\left(1-\alpha_{n}\right) d^{2}\left(y_{n}, \tilde{x}\right)+\alpha_{n}\left(d^{2}\left(f\left(x_{n}\right), \tilde{x}\right)-d^{2}\left(f\left(x_{n}\right), y_{n}\right)\right)+\alpha_{n}^{2} d^{2}\left(f\left(x_{n}\right), y_{n}\right) .
\end{aligned}
$$

By using (2.3) and the Cauchy-Schwarz inequality (2.4), we have

$$
\begin{aligned}
& \alpha_{n}\left(d^{2}\left(f\left(x_{n}\right), \tilde{x}\right)-d^{2}\left(f\left(x_{n}\right), y_{n}\right)\right) \\
& =2 \alpha_{n}\left\{\left\langle\overrightarrow{f\left(x_{n}\right) \tilde{x}}, \overrightarrow{y_{n} \tilde{x}}\right\rangle-d^{2}\left(y_{n}, \tilde{x}\right)\right\} \\
& =2 \alpha_{n}\left\{\left\langle\overrightarrow{f\left(x_{n}\right) f(\tilde{x})}, \overrightarrow{y_{n} \tilde{x}}\right\rangle+\left\langle\overrightarrow{f(\tilde{x}) \tilde{x}}, \overrightarrow{y_{n} \tilde{x}}\right\rangle-d^{2}\left(y_{n}, \tilde{x}\right)\right\} \\
& \leqslant 2 \alpha_{n}\left\{k d\left(x_{n}, \tilde{x}\right) d\left(y_{n}, \tilde{x}\right)+\left\langle\overrightarrow{f(\tilde{x}) \tilde{x}}, \overrightarrow{y_{n}} \vec{x}\right\rangle-d^{2}\left(y_{n}, \tilde{x}\right)\right\} \\
& \left.\leqslant \alpha_{n} k\left(d^{2}\left(x_{n}, \tilde{x}\right)+d^{2}\left(y_{n}, \tilde{x}\right)\right)+2 \alpha_{n}\left\langle\overrightarrow{f(\tilde{x}) \tilde{x}}, \overrightarrow{y_{n} \tilde{x}}\right\rangle-2 \alpha_{n} d^{2}\left(y_{n}, \tilde{x}\right)\right\} \\
& =\alpha_{n} k d^{2}\left(x_{n}, \tilde{x}\right)-\alpha_{n}(2-k) d^{2}\left(y_{n}, \tilde{x}\right)+2 \alpha_{n}\left\langle\overrightarrow{f(\tilde{x}) \tilde{x}}, \overrightarrow{y_{n} \tilde{x}}\right\rangle \\
& =\alpha_{n} k d^{2}\left(x_{n}, \tilde{x}\right)-\alpha_{n}(2-k) d^{2}\left(y_{n}, \tilde{x}\right)+\alpha_{n}\left(d^{2}(f(\tilde{x}), \tilde{x})+d^{2}\left(y_{n}, \tilde{x}\right)-d^{2}\left(f(\tilde{x}), y_{n}\right)\right) \\
& =\alpha_{n} k d^{2}\left(x_{n}, \tilde{x}\right)-\alpha_{n}(1-k) d^{2}\left(y_{n}, \tilde{x}\right)+\alpha_{n}\left(d^{2}(f(\tilde{x}), \tilde{x})-d^{2}\left(f(\tilde{x}), y_{n}\right)\right) \\
& \leqslant \alpha_{n} k d^{2}\left(x_{n}, \tilde{x}\right)+\alpha_{n}\left(d^{2}(f(\tilde{x}), \tilde{x})-d^{2}\left(f(\tilde{x}), y_{n}\right)\right) \text {, }
\end{aligned}
$$


and

$$
d^{2}\left(y_{n}, \tilde{x}\right) \leqslant H^{2}\left(T x_{n}, T \tilde{x}\right) \leqslant d^{2}\left(x_{n}, \tilde{x}\right) .
$$

Substituting (3.7) and (3.8) into (3.6) and simplifying we have

$$
d^{2}\left(x_{n+1}, \tilde{x}\right) \leqslant\left(1-\alpha_{n}(1-k)\right) d^{2}\left(x_{n}, \tilde{x}\right)+\alpha_{n}\left(d^{2}(f(\tilde{x}), \tilde{x})-d^{2}\left(f(\tilde{x}), y_{n}\right)\right)+\alpha_{n}^{2} d^{2}\left(f\left(x_{n}\right), y_{n}\right) .
$$

Putting, in Lemma 2.4, $c_{n}=d^{2}\left(x_{n}, \tilde{x}\right), \gamma_{n}=\alpha_{n}(1-k)$ and

$$
\eta_{n}=\frac{d^{2}(f(\tilde{x}), \tilde{x})-d^{2}\left(f(\tilde{x}), y_{n}\right)+\alpha_{n} d^{2}\left(f\left(x_{n}\right), y_{n}\right)}{1-k}
$$

then (3.9) can be written as

$$
c_{n+1} \leqslant\left(1-\gamma_{n}\right) c_{n}+\gamma_{n} \eta_{n}, \quad \forall n \geqslant 1 .
$$

It follows from conditions (C1), (C2), (C3) and (3.5) that

(i) $\gamma_{n} \in(0,1)$ and $\sum_{n=1}^{\infty} \gamma_{n}=\infty$;

(ii) $\limsup _{n \rightarrow \infty} \eta_{n} \leqslant 0$.

Therefore all conditions in Lemma 2.4 are satisfied. We have $c_{n} \rightarrow 0$ as $n \rightarrow \infty$. This implies that $x_{n}$ converges strongly to $\tilde{x}$, where $\tilde{x}=P_{\text {Fix }(T)} f(\tilde{x})$. This completes the proof of Theorem 3.1.

Remark 3.2. Theorem 3.1 not only gives an affirmative answer to the open question raised by Panyanak and Suantai [15], but also generalizes the corresponding results of Panyanak and Suantai [15, Theorem 3.3], Wangkeeree and Preechasilp [19], Dhompongsa et al. [6], Qin [16], Gunduz et al. [10] and many others.

The following result can be obtained from Theorem 3.1 immediately.

Corollary 3.3. Let $\mathrm{E}$ be a nonempty closed convex subset of a complete $\mathrm{CAT}(0)$ space $\mathrm{X}$, and $\mathrm{T}: \mathrm{E} \rightarrow \mathrm{K}(\mathrm{E})$ be a nonexpansive mapping satisfying the endpoint condition. Suppose that $\mathrm{u}, \mathrm{x}_{1} \in \mathrm{E}$ are arbitrarily chosen and $\left\{\mathrm{x}_{\mathrm{n}}\right\}$ is defined by

$$
x_{n+1}=\alpha_{n} u \oplus\left(1-\alpha_{n}\right) y_{n}, \forall n \geqslant 1,
$$

where $y_{n} \in T\left(x_{n}\right)$ such that $d\left(y_{n}, y_{n+1}\right) \leqslant d\left(x_{n}, x_{n+1}\right)$ for all $n \geqslant 1$ and $\left\{\alpha_{n}\right\}$ is a sequence in $(0,1)$ satisfying $(\mathrm{C} 1)$, (C2) and (C3). Then $\left\{x_{n}\right\}$ converges strongly to the unique nearest point of $u$ in $F i x(T)$.

\section{4. $\mathbb{R}$-Trees}

To avoid the endpoint condition, we prefer to work on $\mathbb{R}$-trees. Although an $\mathbb{R}$-tree is not strong enough to make all nonexpansive mappings having the endpoint condition, but it is strong enough to make our theorems hold without this condition.

Definition 4.1. An $\mathbb{R}$-tree is a geodesic space $X$ such that:

(i) there is a unique geodesic segment $[x, y]$ joining each pair of points $x, y \in X$;

(ii) if $[y, x] \cap[x, z]=\{x\}$, then $[y, x] \cup[x, z]=[y, z]$. By (i) and (ii) we have

(iii) if $u, v, w \in X$, then $[u, v] \cap[u, w]=[u, z]$, for some $z \in X$.

Let $E$ be a closed convex subset of a complete $\mathbb{R}$-tree $(X, d)$ and $T: E \rightarrow B C C(E)$ be a multivalued mapping. Then, by [1, Theorem 4.1], there exists a single-valued mapping $t: E \rightarrow E$ such that $t(x) \in T(x)$ and

$$
\mathrm{d}(\mathrm{t}(\mathrm{x}), \mathrm{t}(\mathrm{y})) \leqslant \mathrm{H}(\mathrm{T}(\mathrm{x}), \mathrm{T}(\mathrm{y})), \quad \forall x, y \in \mathrm{E} .
$$

In this case, we call $t$ a nonexpansive selection of $T$.

Let $f: E \rightarrow E$ be a contraction and fix $x_{1} \in E$. We define a sequence $\left\{x_{n}\right\}$ in $E$ by

$$
x_{n+1}=\alpha_{n} f\left(x_{n}\right) \oplus\left(1-\alpha_{n}\right) y_{n},
$$

where $y_{n}=t\left(x_{n}\right) \in T\left(x_{n}\right)$ for all $n \geqslant 1$. 
Theorem 4.2. Let $\mathrm{E}$ be a nonempty closed convex subset of a complete $\mathbb{R}$-tree $\mathrm{X}$, and $\mathrm{T}: \mathrm{E} \rightarrow \mathrm{BCC}(\mathrm{E})$ be a nonexpansive mapping with $\mathrm{Fix}(\mathrm{T}) \neq \emptyset$. Let $\mathrm{f}: \mathrm{E} \rightarrow \mathrm{E}$ be a contraction with $\mathrm{k} \in(0,1)$ and $\left\{\alpha_{\mathrm{n}}\right\}$ be a sequence in $(0,1)$ satisfying the conditions $(\mathrm{C} 1),(\mathrm{C} 2)$ and $(\mathrm{C} 3)$ in Theorem 3.1. Then the sequence $\left\{x_{n}\right\}$ defined by $(4.2)$ converges strongly to $\tilde{x}=\mathrm{P}_{\mathrm{Fix}(\mathrm{T})}(\mathrm{f}(\tilde{\mathrm{x}}))$.

Proof. By [1, Theorem 4.2], Fix $(\mathrm{t})=$ Fix $(\mathrm{T})$. And the set of fixed points Fix $(\mathrm{T})$ is closed and convex by [12, Proposition 1] and $t$ is nonexpansive by (4.1). Hence the conclusion follows from Theorem 3.1, immediately.

\section{Acknowledgment}

This study was supported by the National Natural Science Foundation of China (Grant No. 11361070) and the Natural Science Foundation of the Center for General Education, China Medical University, Taichung, Taiwan.

\section{References}

[1] A. G. Aksoy, M. A. Khamsi, A selection theorem in metric trees, Proc. Amer. Math. Soc., 134 (2006), 2957-2966. 4, 4

[2] I. D. Berg, I. G. Nikolaev, Quasilinearization and curvature of Aleksandrov spaces, Geom. Dedicata, 133 (2008), $195-218$. $1,2,2$

[3] M. R. Bridson, A. Haefliger, Metric spaces of non-positive curvature, Grundlehren der Mathematischen Wissenschaften [Fundamental Principles of Mathematical Sciences], Springer-Verlag, Berlin, (1999). 2

[4] K. S. Brown, Buildings, Springer-Verlag, New York, (1989). 2

[5] S. Dhompongsa, A. Kaewkhao, B. Panyanak, Browder's convergence theorem for multivalued mappings without endpoint condition, Topology Appl., 159 (2012), 2757-2763. 2

[6] S. Dhompongsa, A. Kaewkhao, B. Panyanak, On Kirk's strong convergence theorem for multivalued nonexpansive mappings on CAT(0) spaces, Nonlinear Anal., 75 (2012), 459-468. 1, 3.2

[7] S. Dhompongsa, W. A. Kirk, B. Panyanak, Nonexpansive set-valued mappings in metric and Banach spaces, J. Nonlinear Convex Anal., 8 (2007), 35-45. 2.1

[8] S. Dhompongsa, B. Panyanak, On $\Delta$-convergence theorems in CAT(0) spaces, Comput. Math. Appl., 56 (2008), $2572-$ 2579. 2.1

[9] K. Goebel, S. Reich, Uniform convexity, hyperbolic geometry, and nonexpansive mappings, Monographs and Textbooks in Pure and Applied Mathematics, Marcel Dekker, Inc., New York, (1984). 2

[10] B. Gunduz, S. H. Khan, S. Akbulut, Common fixed points of two finite families of nonexpansive mappings in Kohlenbach hyperbolic spaces, J. Nonlinear Funct. Anal., 2015 (2015), 13 pages. 3.2

[11] W. A. Kirk, Fixed point theorems in CAT(0) spaces and R-trees, Fixed Point Theory Appl., 2004 (2004), 309-316. 2

[12] J. T. Markin, Fixed points for generalized nonexpansive mappings in R-trees, Comput. Math. Appl., 62 (2011), 4614-4618. 4

[13] A. Moudafi, Viscosity approximation methods for fixed-points problems, J. Math. Anal. Appl., 241 (2000), 46-55. 1

[14] S. B. Nadler, Jr., Multi-valued contraction mappings, Pacific J. Math., 30 (1969), 475-487. 2.7

[15] B. Panyanak, S. Suantai, Viscosity approximation methods for multivalued nonexpansive mappings in geodesic spaces, Fixed Point Theory Appl., 2015 (2015), 14 pages. 1, 1.3, 1.4, 1, 2.6, 3.2

[16] X.-L. Qin, S. Y. Cho, Convergence analysis of a monotone projection algorithm in reflexive Banach spaces, Acta Math. Sci. Ser. B Engl. Ed., 37 (2017), 488-502. 3.2

[17] L. Y. Shi, R. D. Chen, Strong convergence of viscosity approximation methods for nonexpansive mappings in CAT(0) spaces, J. Appl. Math., 2012 (2012), 11 pages. 1

[18] N. Shioji, W. Takahashi, Strong convergence of approximated sequences for nonexpansive mappings in Banach spaces, Proc. Amer. Math. Soc., 125 (1997), 3641-3645. 2.3

[19] R. Wangkeeree, P. Preechasilp, Viscosity approximation methods for nonexpansive mappings in CAT(0) spaces, J. Inequal. Appl., 2013 (2013), 15 pages. 1, 1.1, 1.2, 1, 3.2

[20] R. Wangkeeree, P. Preechasilp, Viscosity approximation methods for nonexpansive semigroups in CAT(0) spaces, Fixed Point Theory Appl., 2013 (2013), 16 pages. 2.2

[21] H.-K. Xu, An iterative approach to quadratic optimization, J. Optim. Theory Appl., 116 (2003), 659-678. 2.4 